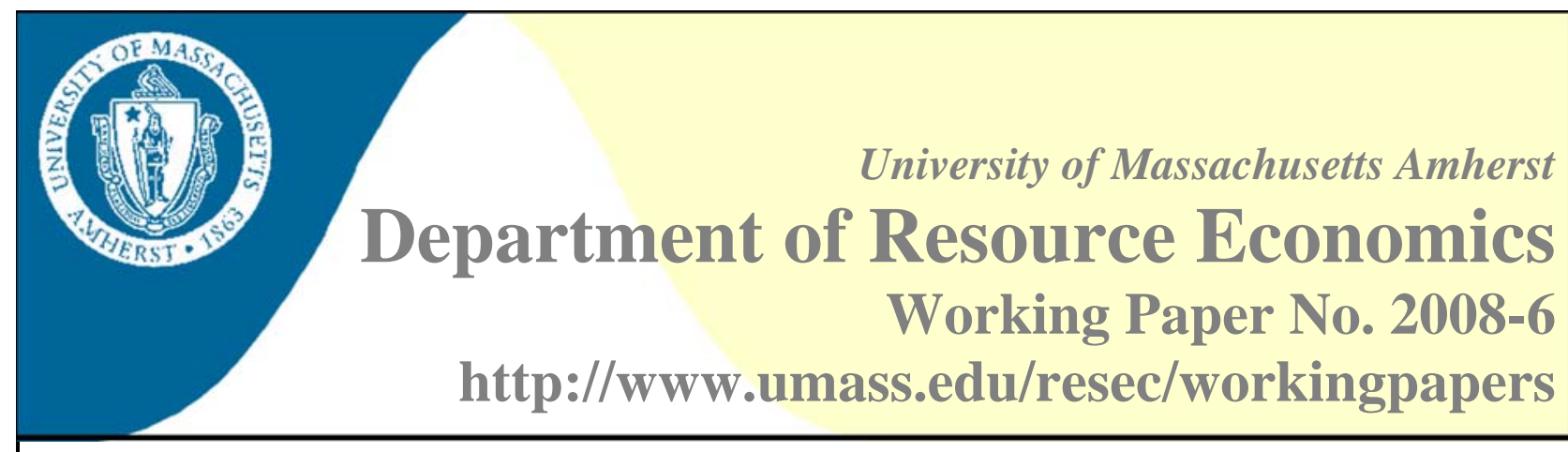

\title{
Understanding Persistent Food Insecurity: A Paradox of Place and Circumstance
}

\author{
Sheila Mammen ${ }^{1}$, Jean W. Bauer ${ }^{2}$, and Leslie Richards ${ }^{3}$
}

Abstract:

Survey data from a USDA-funded multi-state longitudinal project revealed a paradox where rural low-income families from states considered prosperous were persistently more food insecure than similar families from less prosperous states. An examination of quantitative and qualitative data found that families in the food insecure states were more likely to experience greater material hardship and incur greater housing costs than families in the food secure states. Families in the food insecure states, however, did not have lower per capita median incomes or lower life satisfaction than those in the food secure states. A wide range of strategies to cope with food insecurity reported by families in both food insecure and food secure states was examined using the Family Ecological Systems Theory. Families in the food insecure states used several risky consumption reduction strategies such as curbing their appetite and using triage. Families in the food secure states, on the other hand, employed positive techniques involving their human capital.

Keywords: persistent food insecurity, rural low-income families, food coping strategies, family ecological systems, material hardship

JEL Classification: I32

\footnotetext{
${ }^{1}$ Sheila Mammen, Department of Resource Economics University of Massachusetts, 303 Stockbridge Hall

80 Campus Center Way, Amherst, MA 01003-9246

E: smammen@resecon.umass.edu P: 413-545-2470 F: 413-545-5853

${ }^{2}$ Jean W. Bauer, Department of Family Social Sciences

University of Minnesota, 275 McNeal Hall

Minneapolis, MN 55108

E: jbauer@umn.edu P: 612-625-1763

${ }^{3}$ Leslie Richards, Department of Human Development \& Family Sciences

Oregon State University, 322 Milam Hall

Corvallis, OR 97331

E: leslie.richards@oregonstate.edu P: 541-737-1071
} 


\section{UNDERSTANDING PERSISTENT FOOD INSECURITY: A PARADOX OF PLACE AND CIRCUMSTANCE}

Sheila Mammen, Jean W. Bauer, Leslie Richards 


\title{
UNDERSTANDING PERSISTENT FOOD INSECURITY: \\ A PARADOX OF PLACE AND CIRCUMSTANCE
}

\begin{abstract}
Survey data from a USDA-funded multi-state longitudinal project revealed a paradox where rural low-income families from states considered prosperous were persistently more food insecure than similar families from less prosperous states. An examination of quantitative and qualitative data found that families in the food insecure states were more likely to experience greater material hardship and incur greater housing costs than families in the food secure states. Families in the food insecure states, however, did not have lower per capita median incomes or lower life satisfaction than those in the food secure states. A wide range of strategies to cope with food insecurity reported by families in both food insecure and food secure states was examined using the Family Ecological Systems Theory. Families in the food insecure states used several risky consumption reduction strategies such as curbing their appetite and using triage. Families in the food secure states, on the other hand, employed positive techniques involving their human capital.
\end{abstract}

KEY WORDS: persistent food insecurity, rural low-income families, food coping strategies, Family Ecological systems, material hardship 


\section{INTRODUCTION}

The United States (U.S.) is one of the richest nations in the world based on its per capita gross domestic product (UNDP, 2007). However, when compared to other advanced industrial countries in the Organization for Economic Cooperation and Development (OECD), many striking paradoxes emerge in the U.S. We have lower levels of life expectancy and higher levels of infant mortality and child poverty. We spend less on moving families out of poverty, perhaps, the reason for the greater household income inequality found in the U.S. than in most other advanced OECD countries (OECD, n.d.). Our study, using survey data from a U.S. Department of Agriculture (USDA) funded multi-state longitudinal project, suggests that a similar paradox can appear among states in the U.S. as well; low-income rural families in states usually considered prosperous ${ }^{1}$ seem to experience greater food insecurity than those in less prosperous states.

Food security may be defined as families’ consistent and dependable access to sufficient food to maintain an active and healthy life (Nord et al., 2005). Families are considered food insecure when safe and nutritionally adequate food is either not readily available or when they have to resort to extraordinary means to obtain it, such as depending on emergency food supplies or using other coping strategies. If food insecurity persists, it may lead to a variety of problems. For example, children who are food insecure are more vulnerable to physical and mental health problems along with adverse developmental outcomes including poor school performance (Alaimo et al., 2001). Ultimately, if families are unable to meet their food needs in terms of sufficiency, it may erode their quality of life as well as the well-being of the nation as a whole.

Low-income families in the U.S. are more likely to suffer from food insecurity than other families and poverty is a significant predictor of food insecurity (Townsend et al., 2001). While 
the level of food insecurity among households with children is not substantially different between households in metropolitan areas (16\%) and non-metropolitan areas (17\%) (Nord et al., 2005), nevertheless, in the U.S. poverty is disproportionately higher and more persistent in rural areas than in urban areas (Weber and Jensen, 2004). Rural residents, particularly low-income single mothers, are more likely to face issues such as unemployment, underemployment, and low wages (Berry et al., 2008; Dolan et al., 2006; Lichter and Jensen, 2002) making it more difficult for them to escape poverty and, as a result, food insecurity.

The existence of a paradox where rural low-income families are more food insecure in prosperous states compared to those in less prosperous states is not widely seen in other studies. Most studies, using state characteristics as explanatory factors, have consistently found food insecurity in the same states in the Southwest and South (Bartfeld and Dunifon, 2006; Tapogna et al., 2004). One study, however (Edwards et al., 2006), reported high hunger rates in Oregon, in spite of a booming economy, and proposed using standardized demographic and local characteristics such as household structure, income, unemployment, and home ownership to explain state-level differences in hunger.

In this study, we use both quantitative and qualitative data to examine persistent food insecurity among low-income rural families living in seven states in the U.S. using the framework of their personal circumstances and the state in which they live. The questions we address include: 1) Why are some rural low-income families from states generally considered prosperous paradoxically more food insecure? 2) Conversely, why are some poor rural families living in less prosperous states far more food secure? 3) Is food insecurity among low-income rural families with children associated with low life satisfaction? 4) What coping strategies do limited-resource rural families, in general, use to manage food insecurity? The life 
circumstances and food security management strategies used by these families are examined within the context of the Family Ecological Systems Theory.

\section{BACKGROUND AND LITERATURE REVIEW}

Range of severity of food insecurity

For limited-resource families, food insecurity is seldom a sudden one-step occurrence but rather “a progressive series of events” (Connell et al., 2001). In addition, families who experience food insecurity face issues of quality as well as quantity of food. Generally, during the initial phase, low-income families are concerned that they will run out of food before they have the necessary funds to purchase more food. Therefore, their first response to this situation is to decrease the quality of their food by substituting with cheaper foods and reducing the variety of their diets (Sarlio-Lahteenkorva and Lahelma, 2001). This phase is referred to as low food security (formerly, food insecurity without hunger). ${ }^{2}$ If their resource problems persist, along with a reduction in the quality of food, adults in the family may also decrease their intake quantity. While this coping strategy affects adult food consumption, generally the children are not deprived of food supplies. However, if families continue to be unable to resolve their resource problems, they may finally have to resort to decreasing their children's food intake or even skipping meals entirely. This stage when both adults and children face a reduction in food quantity and/or skip meals is referred to as very low food security (formerly, food insecurity with hunger) (Radimer et al., 1990).

\section{Selected household characteristics and food insecurity}

Previous research has presented several household characteristics that are associated with food insecurity. The lack of adequate income is a major reason why families experience food insecurity. More than $42 \%$ of households with income below the Federal poverty line ( $\$ 19,350$ 
for a family of 4 in 2005) were food insecure (Federal Register, 2005; Nord et al., 2005). The most vulnerable of these were single mothers with children; $31 \%$ of such households were food insecure with low or very low food security among adults and children. Another group at risk for food insecurity were non-White households with children; Black and Hispanic households had rates of low and very low food security that were well above the national average (Nord et al., 2005). Also considered particularly susceptible to food insufficiency were families of migrant and seasonal farmworkers (Quandt et al., 2004).

A study of adults living in the southern region of the United States reported that, when compared to those who were food secure, those experiencing food insecurity were more likely to be poorer, younger, a member of a minority race, have less than a high school education, and participate in only one food assistance program (Connell et al., 2001). Using data from the Survey of Income and Program Participation (SIPP) and Survey of Program Dynamics (SPD), Ribar and Hamrick (2003) found that food insecure individuals were more likely to be female household heads, disabled, not have completed high school, unable to stretch consumption costs over time, and possess only low levels of asset income.

Regional differences have also been observed in the incidence of food insecurity. Both low and very low food security were more prevalent in the South and West census regions than in the Northeast and Midwest (Nord et al., 2005). Among states, in 2005, the rates of low food security varied from $6.4 \%$ in North Dakota to $16.8 \%$ in New Mexico. Similarly, rates of very low food security varied from $1.9 \%$ in Delaware to $6.3 \%$ in South Carolina (Nord et al., 2005).

Households in non-metropolitan areas were more likely to experience food insecurity than those in metropolitan areas. Households in the rural south, particularly in Louisiana, were more likely to experience higher levels of food insecurity than the nation as a whole; rural Blacks, and 
especially children in rural female-headed households, were even more vulnerable in this regard (Monroe et al., 2002).

Material hardship

Household income has been the traditional measure of economic well-being used in poverty statistics. However, needs (both basic and non-basic) are not identical across families and, therefore, income alone does not explain if a family can afford housing or adequate food or personal care. Mayer and Jencks (1989) proposed material hardship, as a measure of equal relevance, to be considered along with family income when assessing policies to alleviate poverty. Mirowsky and Ross (1999) refer to the lack of money available to meet family needs for shelter, food, clothing, and medical care as economic hardship. Such privation can cause extreme distress as families that have to juggle limited income among competing needs may decide to pay for housing or medical care at the expense of adequate food. In their study of poor urban mothers, Edin and Lein (1997) reported that employment did not shield mothers from material hardship. Having to make difficult choices, some preferred to run out of food at the end of the month rather than go without medical care.

\section{Housing costs}

Housing expenses, usually the largest share of a household's budget, can be an enormous financial burden for limited-resource families if they have to pay market rent or make mortgage payments. Although the costs may be somewhat lower for those who are living in subsidized housing or sharing housing with a family member or friend, housing expenses can, nonetheless, pose a substantial problem for families if they are required to make a trade-off between housing and food. According to a recent national report, 35\% of households experiencing low food security and 57\% facing very low food security had to choose between food and rent/mortgage 
payment; $44 \%$ living with low food security and $63 \%$ experiencing very low food security had to choose between food and utilities/heating oil. In the case of families with children, $43 \%$ had to face a trade-off between food and rent/mortgage payment while $52 \%$ had to pick between paying for food and paying for utilities (Cohen et al., 2006). Low-income households, likewise, faced greater constraints in acquiring adequate food when their income had to be used for rent or mortgage payments (Kirkpatrick and Tarasuk, 2003).

Edin and Lein (1997) reported that welfare-reliant urban mothers prioritized their spending by paying for housing and purchasing food before attending to other bills. At the same time, working low-income urban mothers spent, on average, double the amount that welfarereliant mothers paid for total housing costs which included rent/mortgage payments and utilities. While these working mothers paid substantially more for housing, they did not spend more on food (Edin and Lein, 1997).

Quality of life and satisfaction with life

Concerns over food sufficiency can affect individuals' mental outlook which is an important dimension of their quality of life or satisfaction with life. Using mothers in a pediatric clinical sample, Casey et al. (2004) found that a positive maternal depression screen was associated with household food insecurity. In another study, mothers and children living in 18 large cities were assessed to be at greater risk of depression if mothers were food insecure; the stress was even greater among families with young children (Whitaker et al., 2006). Hamelin et al. (1999) reported that a lack of food was related to greater stress.

Irish school children, between the ages of 10 and 17, who reported food insufficiency were significantly more likely to suffer from mental and somatic symptoms as well as low life satisfaction (Molcho et al., 2007). When an international comparison was made with school 
children from 32 other countries, a similar association was found between food poverty and low life satisfaction. Finally, in a study of adults, 60 and over, those at risk of malnutrition had significantly lower quality of life (Vailas et al., 1998).

Edwards et al. (2006) opined that the contradiction between Oregon's prosperous economy and its high hunger rate may contribute to greater feelings of relative deprivation among food-insecure families in Oregon than those in states more accustomed to dealing with hunger. This may result in lowered quality of life among such families.

Although Parra-Cardona et al. (2006) did not address the relationship between food insecurity and life satisfaction; nonetheless, using our data set, they examined the life satisfaction of Hispanic migrant families from Michigan. Interestingly, in spite of the many challenges of daily life, these families reported high levels of life satisfaction.

Food insecurity coping and management strategies

Previous research has highlighted a variety of strategies that families utilize to cope with and manage food insecurity. With a few exceptions, these strategies are generally used by all limited-resource families regardless of ethnicity or region of country. Monroe et al. (2002) found that women in the rural south regularly used church and community food pantries, ate what was left after everyone else had eaten, borrowed money from family members and friends, skimped on food, skipped meals entirely, stretched the food budget by eating with relatives or friends, prepared only certain kinds of inexpensive or low quality food, bought large quantities of food by themselves or with others and split it and, if all else failed, asked children to wait until the next morning for food. Low-income families in persistently poor rural areas which included central Appalachia, the Mississippi Delta, the Lower Rio Grande Valley, and Indian reservations 
in South Dakota, relied on their extended families and food banks for food rather than turning to government programs such as food stamps or WIC (Harvey et al., 2002).

Quandt et al. (2004) concluded that better educated farm workers were more successful in using strategies such as saving, budgeting, and economizing when money was tight. Strategies used by migrant families also included stretching their food dollars by going to cheaper stores, buying the most inexpensive foods, using local church food pantries and other food distribution programs, supplementing food supply with wild game and fish, approaching family, friends and employers for loans, and finally, participating in government programs such as WIC and free/reduced-price school lunch.

In many cases, mothers have resorted to reducing their food intake to ensure their children have adequate food (McIntyre et al., 2003). Some mothers sent children to a friend's or relative's home for food, postponed the payment of bills, gave up services such as telephone and cable, and sold or pawned their possessions (Tarasuk, 2001). Hamelin et al. (1999) noted that in order to cope with food insufficiency, low-income families bought food with credit, sold personal belongings, went to usurers, poached animals, and also stole.

\section{Family Ecological Systems Model}

The Family Ecological Theory (Bubolz and Sontag, 1993) often used in child and development research is the underlying theory for our study of family systems approach to food insecurity. Families function in nested systems, collectively referred to as an ecosystem, which integrates the ecological and systems approaches to the study of families. The ecosystem consists of the microsystem, mesosystem, exosystem, and macrosystem, a human development research model conceptualized by Bronfenbrenner (1979; 1986). It emphasizes the natural and social environments of the family and interrelationships among the various systems and subsystems 
(Bubolz and Whiren, 1984) as families live their daily life. The systems are interdependent and the interaction within one system influences and is influenced by all the other systems.

Families and their resources such as human capital, which includes their decision-making abilities regarding food consumption/production, are embedded within the microsystem, the core or principal system for families. The mesosystem refers to extended family members and those resources that are connected to the family by interactions, such as friends and local supports like food pantries. The mesosystem is often viewed as a support system or bridge between the microsystem and the exosystem. The exosystem which consists of the institutional structures, external to the family members, have a direct or indirect influence on the family members and their resources. This would include the cost and availability of local housing as well as food and other community resources that influence the ability of individuals to cope with food insecurity. Finally, the macrosystem consists of the broad ideological values and beliefs of the culture, larger social and economic forces resulting in the designation of states as being either food secure or food insecure, and the various public policies and programs that offer support for businesses, families, and individuals, including federal food policies and programs (HuddlestonCasas and Braun, 2006).

Families use strategies, from across the ecosystem, to cope with food insecurity. These are neither static nor consistently applied by all families; families use strategies that fit into their particular family contexts and are, quite likely, adjusted as their personal circumstances and needs change. For these reasons, the Family Ecological model is an ideal theoretical framework to help explain the coping mechanisms rural families use to manage food insecurity. Drawing on the literature, the authors have developed the following hypotheses: 
H1: Families in the food insecure states are more likely to have lower per capita median incomes than families in the food secure states,

H2: Families in the food insecure states are more likely to experience greater material hardship and incur greater housing costs as a share of their family income, and

H3: Mothers in the food insecure states are more likely to be less satisfied with life than the mothers in the food secure states.

\section{DATA AND METHOD}

Data for this research came from the USDA-funded multi-state longitudinal project, NC223/NC1011, "Rural Low-Income Families: Tracking Their Well-Being and Functioning in the Context of Welfare Reform.”3 To be eligible for the study, families had to have annual incomes at or below 200\% of the Federal poverty line and at least one child under the age of 13 years. Within each rural county, families were chosen to represent the diversity in the types of families with children who were considered low-income, with Hispanic mothers being over sampled. The mothers were recruited through programs that serve low-income families including the Food Stamp Program, Supplemental Program for Women, Infants, and Children (WIC), food pantries, survival centers, housing authority programs, and welfare-to-work programs. This purposive sampling limits the ability to generalize the results. Nevertheless, the findings will provide useful insight on how low-income rural families manage food insecurity.

The 13 states that were part of this study represented all regions of the country: California, Indiana, Kentucky, Louisiana, Massachusetts, Maryland, Michigan, Minnesota, Nebraska, New Hampshire, New York, Ohio, and Oregon. Based on the USDA's measurement method, the food security status of each family was computed using data collected in three waves, from August 1999 to July 2002. Figure I illustrates the percent of food insecure families, 
at each wave of data collection, in the four least food secure states (Massachusetts, Michigan, Minnesota, and Oregon) and the three most food secure states (California, Louisiana, and Nebraska). A striking contrast is highlighted between the least food secure states (hence forward, food insecure states) and the most food secure states (hence forward, food secure states). As can be seen further in Table 1, a smaller percentage of families were persistently food insecure, ${ }^{4}$ although, food insecure states clearly had much higher rates of persistent food insecurity (Massachusetts [44\%], Michigan [25\%], Minnesota [25\%], Oregon [20\%]) than did the food secure states (California [10\%], Louisiana [0\%], and Nebraska [0\%]).

\section{Sample description}

The sample consisted of families who participated in all three waves of interviews; 81 families in the four food insecure states and 54 families in the three food secure states. Table 1 presents the percentage of rural low-income families who were persistently food insecure in both food insecure and secure states compared to the prevalence rate of food insecurity of all families in their respective states during the same time frame, 2000-2002. Surprisingly, with the exception of Oregon, the states that appear the most food insecure in this study are among the more food secure nationally and those that seem to be food secure in this study are far more food insecure nationally; hence, the paradox.

An income index, a ratio of these rural families' median annual income to the median annual income of the county in which they reside, was computed (see Table 1). Two patterns may be observed from the income index. Firstly, at best, the median annual income of our rural low-income families is about half the median annual income of all families in their respective counties (range is from $20 \%$ to $56 \%$ ). Secondly, there is no discernible distinction in the income 
index between families in the food insecure and food secure states; the index does not provide any particular insight into the apparent paradox in food insecurity.

Table 2 summarizes the demographic characteristics of our sample. Mothers in the food insecure states were slightly older (median age of 32 at the time of wave one interview) than the mothers in the food secure states (median age of 28). In the food insecure states, $60 \%$ of the mothers were White while the rest were mostly Hispanic. There was more ethnic diversity among the mothers in the food secure states: $43 \%$ Hispanic, 32\% White, and 17\% AfricanAmerican. Regardless of food security status, over half of all mothers were married or partnered, however, slightly more mothers were married or living with a partner in the food secure states compared to those in the food insecure states.

The majority of mothers in both food insecure states (65\%) and food secure states (87\%) had at least a high school education. However, about one-third of mothers in the food insecure states (35\%) had less than a high school education while this was true of only $13 \%$ of mothers in the food secure states. Over one-third of the mothers, in both food secure and insecure states had three or more children. While a majority of women worked, the women in the food secure states were more likely to work. In the case of spouses/partners, a larger proportion of them worked in all three waves in the food secure states. Interestingly families in the food insecure states had a higher median income than those in the food secure states in wave one. However, this pattern was reversed in waves two and three; families in the food secure states had higher median income. In all three waves, a larger proportion of families in the food secure states (between a quarter and one-third) co-resided with others, such as extended family members, when compared to those in the food insecure states (under 20\%). 


\section{RESULTS}

Comparison of low-income rural families in food insecure and food secure states

In order to better understand the differences between rural low-income families in the food insecure and food secure states, a few key elements of their lives were first examined. These include the per capita median family income, material hardship faced by families, and housing costs as a share of family income, all of which match elements in other studies. Secondly, mothers' perceived satisfaction with life in the food insecure states was compared to that of mothers in the food secure states. Finally, the coping strategies of families in the food insecure and food secure states were gleaned from their qualitative responses.

Per capita median family income

Per capita family income was selected based on the assumption that it was a better measure of income-to-needs based on family size. However, a clear-cut picture did not emerge when the annual per capita median family incomes of families in food insecure states were compared to that of families in food secure states (see Table 3). With the exception of wave 2, per capita median incomes of families in the food insecure states were higher than that of families in the food secure states ([W1: food insecure, \$3,852; food secure, \$3,193] [W2: food insecure, $\$ 4,850$; food secure, $\$ 5,236$ ] [W3: food insecure, $\$ 5,551$; food secure, $\$ 5,116]$ ). While families in the food secure states had greater per capita incomes in wave 2, this difference (\$386) was not as great as it was in wave $1(\$ 659 ; \mathrm{p}<0.05)$ and wave $3(\$ 435 ; \mathrm{ns})$ when families in food insecure states had higher per capita incomes (Mann-Whitney U-test of probability that median income is different between food insecure and food secure families; $\mathrm{W} 1: \mathrm{p}=.032 ; \mathrm{W} 2: \mathrm{p}=.371$; W3: $\mathrm{p}=.082$ ). Also, while there was a yearly increase in income among families in the food 
insecure states, those in the food secure states saw their income rise substantially in wave 2, only to have it decline in wave 3 .

Material hardship faced by families

A hardship index was constructed using responses to the question, "In the past year, has there been a time when you had a hard time making ends meet or paying for necessities? Did you have trouble paying for (coded yes or no): (a) food (b) clothing (c) medical care (d) dental care (e) medicines and (f) other.” Families in the food insecure states suffered greater material hardship than those in the food secure states and this was the case in all three waves; the differences in material hardships were statistically significant in wave 1 and wave 3 (W1: t(133) $=2.199, \mathrm{p}=.015$ one-tailed; $\mathrm{W} 2: \mathrm{t}(133)=1.484, \mathrm{p}=.070$ one-tailed; $\mathrm{W} 3: \mathrm{t}(133)=2.677, \mathrm{p}=$ .004 one-tailed). Furthermore, while the hardship index for families in the food secure states declined steadily from wave 1 to wave 3 , families in the food insecure states first experienced a decline between wave 1 and wave 2, after which their material hardship increased between wave 2 and wave 3.

Total housing costs as share of annual family income

The housing cost share of annual family income, the measure we used for this analysis, was the amount that low-income rural families spent on rent/mortgage, gas/oil, and electric payments. Compared to families in the food secure states, those in the food insecure states spent more of their income on housing costs in all three waves; about one-third of income during the first two waves followed by $26 \%$ in wave 3 . Families in the food secure states, on the other hand, averaged 22\% percent of their household income on housing costs in waves 1 and 2, and only 16\% $(\mathrm{p}<0.05)$ during wave $3(\mathrm{~W} 1: \mathrm{t}(125)=1.300, \mathrm{p}=.098$ one-tailed; $\mathrm{W} 2: \mathrm{t}(111)=1.456, \mathrm{p}=$ .074 one-tailed; W3: $\mathrm{t}(121)=2.645, \mathrm{p}=.005$ one-tailed $)$. 


\section{Mothers' satisfaction with life}

Table 3 presents the findings when respondents were asked, “Overall, how satisfied are you with your life right now?” Respondents selected from: (1) very dissatisfied, (2) dissatisfied, (3) mixed feelings, (4) satisfied, (5) very satisfied. Satisfaction with life was measured in each wave. Families in the food secure states appeared to be marginally more satisfied in all the three waves than families in the food insecure states. In wave 1 , there was a greater disparity between the two groups as families in the food insecure states were more likely to report mixed feelings with their life than those in food secure states who reported being more satisfied. However, in waves 2 and 3, all families were generally closer to being satisfied with their life (W1: t(131) = $-2.177, \mathrm{p}=.016$ one-tailed; $\mathrm{W} 2: \mathrm{t}(128)=-1.591, \mathrm{p}=.057$ one-tailed; W3: $\mathrm{t}(131)=-0.660, \mathrm{p}=$ .256 one-tailed).

Coping strategies of families in food insecure and food secure states

From a systematic examination of open-ended qualitative responses, it was clear that low-income rural families used a variety of strategies to cope with and manage food insecurity. Table 4 presents, in descending order, the selection of a strategy (whether or not our families adopted the strategy) as well as the intensity of use (how often each family used the strategy) between families in the food insecure and food secure states during all three waves of data collection. The differences between food management strategies used by families in the food insecure and food secure states were found in their ranking; the selection of strategies aligned closely with the intensity of use among families within the two groupings of states except for the selection of government programs in the food secure states and the human capital strategy as the last strategy for food insecure states. 
The strategy identified and used most often by families from both food insecure and food secure states was shopping techniques which involved activities such as use of coupons, bulk buying, and selecting off-brands. The second strategy that families in the food insecure states depended on, in terms of selection and intensity, was community supports such as food banks, food pantries, and church or other non-profit agencies. Families from the food secure states, on the other hand, were able to rely on eating at the homes of extended family members, a strategy seldom mentioned by participants in food insecure states.

Another point of departure between families in food insecure and food secure states was also evident in their third coping strategy. While families from the food secure states utilized a variety of human capital techniques such as gardening, freezing, canning, and preparing big soups or stews, families in food insecure states turned, instead, to consumption reduction behaviors. Examples of these behaviors that were reported included dieting (using dieting or “needing to lose weight” to manage or reduce hunger), curbing appetite (smoking, drinking coffee, ignoring mealtimes), and triage (making deliberate choices as to which family members eat first; often, children first then adult males). The human capital strategy is one that likely stretches resources, while the consumption reduction strategy is, at best, a risky approach to feeding one's family.

Money techniques, such as using credit cards, juggling bills, and writing bad checks, was cited as the fourth most selected and intensively used strategy by families in both food insecure and food secure states. Although mentioned far less often, the use of government programs (food stamps, WIC) was yet another identified strategy that was intensively used by many families. 


\section{DISCUSSION}

\section{Explaining the paradox}

The families in this study seem to contradict traditional notions of the food security status of rural low-income families living in states generally considered prosperous. The most food insecure and the least food insecure states in the data base do not conform to national USDA figures. This apparent contradiction may be explained by some of the sample household characteristics that are unique to the families in the food insecure states. First, a substantial proportion of them who were Hispanic were mostly migrant or seasonal farmworkers. As previously noted by Quandt et al. (2004), this points to an obvious irony; these families are more vulnerable to food insufficiency even though many of them are engaged in agricultural production.

Some of the characteristics highlight barriers that families in the food insecure states may face. A larger proportion of mothers in the food insecure states did not have a high school education. These mothers were slightly less likely to be married or partnered. Likewise, in terms of employment status, mothers and their spouses/partners in the food insecure states were slightly less likely to work. Finally, at each wave, families in the food insecure states were less likely to co-reside with others, including extended family members. It is plausible that living with others may ameliorate the burden of food insufficiency.

If income is the key to explaining why families in food insecure states lack sufficient food, it is conceivable that their per capita income would be lower than that of families living in the food secure states. However, this was not the case in our sample. It is possible that the higher income of food insecure families may have caused them to be ineligible for federal programs, such as food stamps. Or, perhaps they were eligible, but received so few benefits that it did not 
prevent them from experiencing food insecurity. Regardless of the reason, the results confirm the findings of previous studies (Edin and Lein, 1997; Mayer and Jencks, 1989; Mirowsky and Ross, 1999) that income by itself cannot explain food insufficiency.

A better predictor of food adequacy appears to be an index of material hardship; those families in the food insecure states experienced a higher degree of material hardship in all three waves than the families in the food secure states. This suggests that needs are not identical across families and, additionally, when families encounter material hardships, they are more likely to face issues of food security as well.

Families in the food insecure states spent a greater proportion of their income on housing costs. Three out of four of the food insecure states (Massachusetts, Michigan and Minnesota) are ones that often suffer severe winter weather. Even if their heating bills were subsidized, these low-income rural families may have incurred higher housing costs. This finding supports the conclusion of other studies (Cohen et al., 2006; Kirkpatrick and Tarasuk, 2003) that when limited resource families have to pay high housing costs, their ability to afford adequate food may be curtailed if they are required to make a trade-off between housing and food.

Regardless of whether the families were from food insecure or food secure states, they seemed closer to being satisfied than dissatisfied with their life. This "inflated" sense of life satisfaction is somewhat surprising given their circumstance and contradicts the findings of previous studies (Casey et al., 2004; Hamelin et al., 1999; Molcho et al., 2007; Whitaker et al., 2006) which have found an association between food insecurity and low life satisfaction. It does, however, mirror the findings of Parra-Cardona, et al. (2006) of Hispanic migrant families, from the Michigan sample of our study, who expressed a high level of life satisfaction in spite of the daily challenges they face. 
Explaining food coping strategies with the Family Ecological Systems Model

According to the Family Ecological Systems Model (Bubolz and Sontag, 1993), families operate within nested systems and their interaction with one system affects the other systems (Bronfenbrenner, 1986). When faced with food inadequacy, rural low-income families are not dissimilar to other food insecure families elsewhere. They seem to practice the same set of universal strategies to cope with food insufficiency, adapting and adjusting them to fit their unique family circumstances within their microsystem. The coping techniques that they consider appropriate to their families are drawn from across the ecosystem. As the findings have shown, some of the food coping strategies that they use are not, by their nature, positive. Indeed, these families may be experiencing what Radimer et al. (1990) have referred to as very low food security. These strategies, negative as they may be, are nevertheless being used in an effort to produce a positive outcome, i.e. provide food for their families.

The most often adopted and widely used strategy in both food insecure and food secure states involved shopping techniques. This strategy of relying on their decision-making skills, part of the microsystem, appeared to enable rural limited resource families to stretch their food dollar to some extent.

The second reported food coping strategy, involving the mesosystem (the bridge between systems), was different for the families in the food insecure and food secure states. While families in the food secure states were able to avoid hunger by eating with others (usually with extended family members, less often with friends), those in food insecure states relied, instead, on external sources of community support such as food pantries and other food sources. Extended family may not be a viable option for families in the food insecure states either by 
default (no extended family members close by) or by design (extended family members are unable to assist them or they are not personally close).

The third most frequently selected and intensively used strategy among families in the food secure states was based on their ability to marshal their human capital whereas families in the food insecure states turned to various consumption reduction behaviors which had far less positive consequences. Utilizing one’s human capital to procure food supplies appears life affirming while the dieting, appetite curbing, and triage behaviors adopted by families in the food insecure states convey a sense of desperation and, perhaps, the higher degree of food insecurity that they may face. Families in the food secure states never cited consumption reduction behaviors as a mechanism to manage when food was insufficient. Interestingly, once again rural low-income families, regardless of food security status, were more likely to fall back on the microsystem.

Use of the exosystem was evident in the money techniques that were cited as the fourth most frequently identified and intensively used food coping strategy by both sets of families. These are notable in that there are negative implications associated with them since the families are buying food on credit, passing bad checks, or juggling bills. In the short run, these strategies may enable low-income rural families to meet their food needs however, in the long run, they may pose other problems for them.

Interestingly, using government programs or the macrosystem was the last food management strategy mentioned by both sets of families. Clearly these rural low-income families preferred to depend on themselves and their abilities (their microsystem), on extended family and friends and, finally, on local community groups (their mesosystem) before they turned to the federal government (the macrosystem). This supports the findings of Harvey et al. (2002) that 
low-income rural families would rather lean on their kin than on the government. Most policies assume that families would readily turn to the macrosystem and seek outside help. However, these families were more likely to rely on the micro and mesosystems rather than cross over to the next system level for support.

\section{CONCLUSION AND POLICY IMPLICATIONS}

The results of our study highlight a paradox about food insecurity that may be seen in some communities: more rural low-income families in prosperous states appear to experience greater persistent food insecurity than those in less prosperous states. The mothers in the food insecure states were more likely to be less educated, less likely to have a partner and, also, less likely to be employed themselves or have a partner who was employed.

Per capita income did not explain the difference between the families in the food insecure states and those in the food secure states. Therefore, the results did not support our hypothesis that per capita income among families in the food insecure states would be lower than that among families in the food secure states.

An index of material hardship, on the other hand, indicated that families in the food insecure states faced greater difficulties trying to make ends meet and pay for necessities. In addition, a greater proportion of their income was spent on housing costs than that of families in the food secure states. These findings lend credence to our second hypothesis that families in food insecure states are more likely to experience greater material hardship and face greater housing costs. It is conceivable that in trying to meet the many financial demands of daily life, families make a trade-off between food and other expenses. Thus, policymakers should not assume that low-income families in prosperous states are better off than those in less prosperous states. Instead it is important that they consider the realities that families encounter, which often 
results in financial juggling, because of the state-by-state variation in the cost of many basic necessities.

Based on the results of previous studies, we hypothesized an association between food insecurity and low life satisfaction. Indeed, as theorized by Edwards et al. (2006), food insecure families residing in prosperous states may experience an even lower quality of life compared to similar families in less prosperous states. The uniqueness of our method of sample selection and the presence of so many Hispanic families may have contributed to the fact that the rural lowincome families in the food insecure states did not report lower levels of life satisfaction.

A wide array of coping strategies was reported by families in the food insecure and food secure states. One critical observation is that families in the food insecure states used several dangerous consumption reduction strategies such as dieting, curbing their appetite, and triage. Interestingly, regardless of food security status, these rural low-income families were more likely to rely initially on those strategies within the microsystem and the mesosystem i.e. they used various human capital skills, sought help from extended family, and turned to the local community. In contrast, federal programs seemed to be their last resort. The reliance on personal solutions, be they positive or negative, and the desire to stay within a narrower range of systems may be considered commendable to some. However, it raises questions as to why, in the face of persistent food insecurity, rural low-income families prefer this, even when the outcome may be negative such as curbing their appetite.

Our findings point to persistent food insecurity among these rural low-income families as a consequence of place and personal circumstances. In order to address and rectify the paradox of food insecurity, policymakers should examine federal assistance programs. Are they reaching 
those for whom they are intended, are these programs adequate, and do we have families that may need some other type of assistance? 


\section{NOTES}

${ }^{1}$ To determine prosperous states, we ranked the states in our data set according to their infant mortality rate, percent of residents with bachelor's degree, and fiscal capacity index. (States with high fiscal capacity have a relatively high capability to cover their expenditure needs using their own resources while those with low fiscal capacity have a low level of revenue-raising capacity given what it would cost to provide a standard set of public services to their citizens ([Rueben et al., 2006]). Based on these indicators, California, Massachusetts, Minnesota, and Oregon may be considered prosperous while Louisiana, Michigan, and Nebraska may be considered less prosperous.

${ }^{2}$ USDA describes ranges of food insecurity as "low food security” and "very low food security." These labels replaced "food insecurity without hunger" and "food insecurity with hunger" respectively in 2006. (For the USDA's new labels see: http://www.ers.usda.gov/Briefing/FoodSecurity/labels.htm). We have used the terms “food insecure”, “food insecurity”, “food insufficiency”, and “food inadequacy” interchangeably as overall terms to describe the general state of families who experience either low food security or very low food security.

${ }^{3}$ For the complete project description, see (Bauer, 2004, pp. 1-4) and http://fsos.cehd.umn.edu/projects/rfs.html.

${ }^{4}$ For purposes of this study, families were considered persistently food insecure if they were food insecure in all three waves of data collection. 


\section{Acknowledgments}

This research was supported in part by USDA/CSREES/NRICGP Grant Number 200135401-10215 \& 2002-35401-11591, 2004-35401-14938. Data were collected in conjunction with the cooperative multi-state research project, NC-223/NC-1011, “Rural Low-Income Families: Monitoring Their Well-being and Functioning in the Context of Welfare Reform.” Cooperating states are California, Indiana, Kentucky, Louisiana, Massachusetts, Maryland, Michigan, Minnesota, Nebraska, New Hampshire, New York, Ohio, and Oregon.

The authors gratefully acknowledge the assistance of undergraduate research assistants, Peter St. Marie and Thomas Martin, both at the University of Massachusetts Amherst, and Seohee Son, graduate student at the University of Minnesota. 


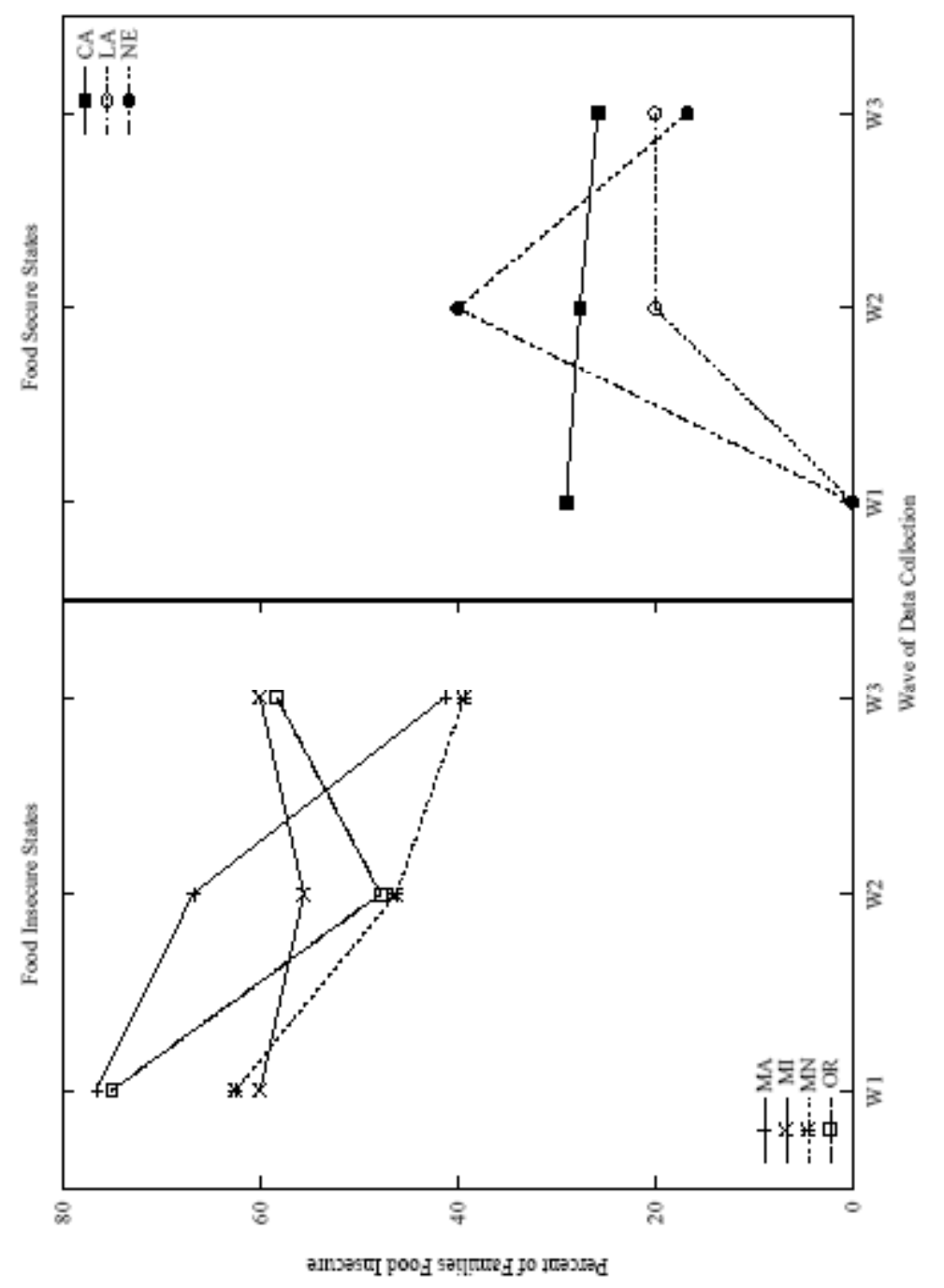

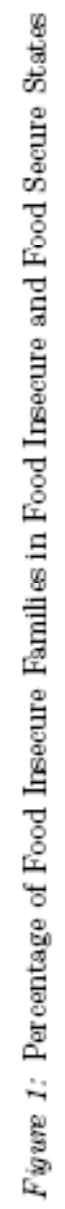




\section{TABLE 1}

Comparison of prevalence of persistent food insecurity and median family income of families in food insecure and food secure states with census data

\begin{tabular}{|c|c|c|c|c|c|c|c|}
\hline \multirow[b]{2}{*}{ State } & \multicolumn{2}{|c|}{$\mathrm{NC} 1011^{\mathrm{a}}(\mathrm{N}=13)$} & \multicolumn{2}{|c|}{$\mathrm{USDA}^{\mathrm{b}, \mathrm{c}}(\mathrm{N}=50)$} & \multicolumn{2}{|c|}{ Median annual family income (\$) } & \multirow[b]{2}{*}{$\begin{array}{c}\text { Income } \\
\text { index }^{\mathrm{i}}\end{array}$} \\
\hline & $\begin{array}{c}\text { \% Food } \\
\text { insecure } \\
\text { persistently }\end{array}$ & $\begin{array}{l}\text { Ranking by } \\
\text { food } \\
\text { insecurity }^{\mathrm{d}}\end{array}$ & $\begin{array}{l}\% \text { Food } \\
\text { insecure }\end{array}$ & $\begin{array}{l}\text { Ranking by } \\
\text { food } \\
\text { insecurity }\end{array}$ & NC1011 W1 ${ }^{\mathrm{f}}$ & County (1999) $)^{\mathrm{g}, \mathrm{h}}$ & \\
\hline \multicolumn{8}{|l|}{ Food insecure } \\
\hline $\operatorname{MA}(n=16)$ & 43.8 & 1 & 6.4 & 50 & 12,711 & 50,915 & 0.25 \\
\hline MI $(n=12)$ & 25.0 & 2 & 9.2 & 33 & 20,784 & 40,602 & 0.51 \\
\hline $\mathrm{MN}(\mathrm{n}=28)$ & 25.0 & 2 & 7.1 & 47 & 12,906 & 54,001 & 0.24 \\
\hline OR $(n=25)$ & 20.0 & 4 & 13.7 & 7 & 22,560 & 40,197 & 0.56 \\
\hline \multicolumn{8}{|l|}{ Food secure } \\
\hline CA $(n=30)$ & 10.0 & 12 & 11.7 & 20 & 15,486 & 39,314 & 0.39 \\
\hline LA $(n=11)$ & 0.0 & 13 & 13.1 & 9 & 7,080 & 35,689 & 0.20 \\
\hline$N E(n=13)$ & 0.0 & 13 & 10.7 & 24 & 18,600 & 42,260 & 0.44 \\
\hline
\end{tabular}

${ }^{\mathrm{a}}$ Percentage of families food insecure for all three waves. ${ }^{\mathrm{b}}$ Includes both low and very low food security. ${ }^{\mathrm{c}}$ USDA; Economic Research Report No. 29. ${ }^{\mathrm{d}}$ Rankings are 1, most food insecure, to 13, least food insecure. ${ }^{\mathrm{e}}$ Rankings are 1 , most food insecure, to 50, least food insecure. ${ }^{\mathrm{f}}$ Income figures are for wave 1 data collection, $1999 .{ }^{\mathrm{g}}$ Values are averages of Census median income data for the counties where respondents resided. ${ }^{\mathrm{i}}$ US Census Bureau; Census 2000; Summary File 3; P77. ${ }^{\mathrm{i}}$ Income index is ratio of NC1011 median annual income, in wave 1, to county level median annual income 
TABLE 2

Socio-demographic characteristics of mothers by wave and food security status

\begin{tabular}{|c|c|c|c|c|c|c|}
\hline & \multicolumn{2}{|c|}{ W1 (\%) } & \multicolumn{2}{|c|}{ W2 (\%) } & \multicolumn{2}{|c|}{ W3 (\%) } \\
\hline & FIS & FSS & FIS & FSS & FIS & FSS \\
\hline \multicolumn{7}{|l|}{ Age } \\
\hline Under 25 & 21.0 & 35.8 & $16.2^{*}$ & $34.0 *$ & 10.1 & 16.7 \\
\hline $25-45$ & 74.1 & 62.3 & 77.9 & 62.3 & 82.3 & 79.6 \\
\hline Over 46 & 4.9 & 1.9 & 5.9 & 3.8 & 7.6 & 3.7 \\
\hline Median age (years) & 32.0 & 28.5 & 32.5 & 29.0 & 33.0 & 30.0 \\
\hline \multicolumn{7}{|l|}{ Ethnicity } \\
\hline White, non-Hispanic & $58.8 *$ & $33.3 *$ & - & - & - & - \\
\hline Hispanic & 35.0 & 42.6 & - & - & - & - \\
\hline African American & 0.0 & 16.7 & - & - & - & - \\
\hline Other & 6.3 & 7.4 & - & - & - & - \\
\hline \multicolumn{7}{|l|}{ Marital status } \\
\hline Married/living with a partner & 54.3 & 57.4 & 55.6 & 70.4 & 59.3 & 64.8 \\
\hline Divorced/separated & 25.9 & 20.4 & 23.5 & 11.1 & 21.0 & 13.0 \\
\hline Single & 19.8 & 22.2 & 21.0 & 18.5 & 19.8 & 22.2 \\
\hline \multicolumn{7}{|l|}{ Education } \\
\hline More than high school & $43.2^{*}$ & $68.5^{*}$ & - & - & - & - \\
\hline High school & 22.2 & 18.5 & - & - & - & - \\
\hline Less than high school & $34.6^{*}$ & $13.0 *$ & - & - & - & - \\
\hline \multicolumn{7}{|l|}{ Number of children } \\
\hline One & 29.6 & 27.8 & 33.3 & 25.9 & 30.9 & 25.9 \\
\hline Two & 32.1 & 33.3 & 27.2 & 37.0 & 29.6 & 29.6 \\
\hline Three or more & 38.3 & 38.9 & 39.5 & 37.0 & 39.5 & 44.4 \\
\hline \multicolumn{7}{|l|}{ Mother working status } \\
\hline Working & 61.7 & 63.0 & 61.6 & 72.2 & 62.2 & 66.7 \\
\hline Not working & 38.3 & 37.0 & 38.4 & 27.8 & 37.8 & 33.3 \\
\hline \multicolumn{7}{|l|}{ Spouse/partner working status } \\
\hline Working & 86.4 & 93.5 & 91.9 & 97.4 & 75.6 & 82.9 \\
\hline Not working & 13.6 & 6.5 & 8.1 & 2.6 & 24.4 & 17.1 \\
\hline \multicolumn{7}{|l|}{ Living with others } \\
\hline Yes & 17.1 & 31.9 & $13.0^{*}$ & $36.0 *$ & 15.6 & 25.0 \\
\hline No & 82.9 & 68.1 & $87.0^{*}$ & $64.0 *$ & 84.4 & 75.0 \\
\hline \multicolumn{7}{|l|}{ Monthly income $^{\mathrm{a}}$} \\
\hline Less than $\$ 1,000$ & 34.6 & 42.6 & 25.9 & 18.5 & 17.3 & 29.6 \\
\hline$\$ 1,000-\$ 1,499$ & 17.3 & 16.7 & 19.8 & 11.1 & 25.9 & 13.0 \\
\hline$\$ 1,500-\$ 1,999$ & 22.2 & 20.4 & 17.3 & 13.0 & 11.1 & 16.7 \\
\hline$\$ 2,000-\$ 2,499$ & 17.3 & 9.3 & 14.8 & 11.1 & 17.3 & 7.4 \\
\hline More than $\$ 2,500$ & 8.6 & 11.1 & $22.2 *$ & $46.3^{*}$ & 28.4 & 33.3 \\
\hline Median income (\$) & 1,338 & 1,184 & $1,599 *$ & $2,375 *$ & 1,678 & 1,739 \\
\hline
\end{tabular}


Note: For all three waves, food insecure states (FIS) $\mathrm{N}=81$; food secure states (FSS) $\mathrm{N}=54$.

Asterisks indicate values (within a wave) which are statistically different at the 5\% level, between food insecure and food secure states.

${ }^{a}$ Monthly and median income are in current dollars at the time of each wave. 
TABLE 3

Comparison of selected characteristics between families in food insecure and food secure states

\begin{tabular}{|c|c|c|c|}
\hline & W1 & W2 & W3 \\
\hline \multicolumn{4}{|c|}{ Annual median family per capita income (\$) } \\
\hline Food insecure & $3852_{a}(81)$ & $4850_{a}(81)$ & $5551_{a}(81)$ \\
\hline Food secure & $3193_{b}(54)$ & 5236 a (54) & $5116_{a}(54)$ \\
\hline \multicolumn{4}{|c|}{ Index of material hardship $^{c}$} \\
\hline Food insecure & $2.42_{a}(81)$ & $1.52_{\mathrm{a}}(81)$ & $1.71_{\mathrm{a}}(81)$ \\
\hline Food secure & $1.72_{b}(54)$ & $1.10_{\mathrm{a}}(54)$ & $0.90_{\mathrm{b}}(54)$ \\
\hline \multicolumn{4}{|c|}{ Total housing costs as a share of income (\%) } \\
\hline Food insecure & $31_{\mathrm{a}}(75)$ & $32_{a}(73)$ & $25_{a}(75)$ \\
\hline Food secure & $22_{a}(52)$ & $22_{a}(40)$ & $16_{b}(48)$ \\
\hline \multicolumn{4}{|c|}{ Mother's satisfaction with life ${ }^{\mathrm{d}}$} \\
\hline Food insecure & $3.49_{a}(80)$ & $3.69 \mathrm{a}(77)$ & $3.71_{\mathrm{a}}(79)$ \\
\hline Food secure & $3.83_{b}(53)$ & $3.94_{a}(53)$ & $3.81_{\mathrm{a}}(54)$ \\
\hline
\end{tabular}

Note: Numbers in parentheses are $\mathrm{N}$ values.

Values in the same column that do not share subscripts are statistically different at the $5 \%$ level, between food insecure and food secure states.

${ }^{\mathrm{c}}$ On a scale of 1 , least material hardship, to 6, greatest material hardship. ${ }^{\mathrm{d}} \mathrm{On}$ a scale of 1 , very dissatisfied with life, to 5 , very satisfied with life. 


\section{TABLE 4}

Food coping/management strategies of rural low-income families in food insecure and food secure states

Selection of strategy by rank

Intensity of use by rank

\begin{tabular}{|c|c|c|c|}
\hline Food insecure states & Food secure states & Food insecure states & Food secure states \\
\hline $\begin{array}{l}\text { 1. Shopping } \\
\text { techniques }\end{array}$ & $\begin{array}{l}\text { 1. Shopping } \\
\text { techniques }\end{array}$ & 1. Shopping techniques & $\begin{array}{l}\text { 1. Shopping } \\
\text { techniques }\end{array}$ \\
\hline 2. Community support & $\begin{array}{l}\text { 2. Meals with } \\
\text { extended family }\end{array}$ & 2. Community support & $\begin{array}{l}\text { 2. Meals with } \\
\text { extended family }\end{array}$ \\
\hline $\begin{array}{l}\text { 3. Consumption } \\
\text { reduction behaviors }\end{array}$ & 3. Human capital & $\begin{array}{l}\text { 3. Consumption } \\
\text { reduction behaviors }\end{array}$ & 3. Human capital \\
\hline 4. Money techniques & $\begin{array}{l}\text { 4. Money techniques } \\
\text { and Meals with } \\
\text { friends }\end{array}$ & 4. Money techniques & 4. Money techniques \\
\hline $\begin{array}{l}\text { 5. Government } \\
\text { programs }\end{array}$ & - & 5. Human capital & $\begin{array}{l}\text { 5. Government } \\
\text { programs }\end{array}$ \\
\hline
\end{tabular}

Note: Shopping techniques: use of coupons, bulk buying, and selecting off-

brands. Community support: use of food banks, food pantries, and church or other non-profit agencies. Meals with extended family: eating at the homes of family members. Human capital: gardening, freezing, canning, and preparing big soups or stews. Consumption reduction behaviors: dieting (using dieting or "needing to loose weight” to manage or reduce hunger), curbing appetite (smoking, drinking coffee, ignoring mealtimes), and triage (making deliberate choices as to which 
family members eat first; often, children first then adult males). Money

techniques: using credit cards, juggling bills, writing bad checks. Government programs: food stamps, WIC. 


\section{References}

Alaimo, K., Olson, C. M., Frongillo, E. A. \& Briefel, R. R. (2001). Food insufficiency, family income, and health in US preschool and school-aged children. American Journal of Public Health, 91, 781-786.

Bartfeld, J. \& Dunifon, R. (2006). State-Level Predictors of Food Insecurity among Households with Children. Journal of Policy Analysis and Management, 25, 921-942. DOI 10.1002/pam.20214

Bauer, J. W. (2004). Basebook Report. Low-income rural families: Tracking their well-being and functioning in the context of welfare reform. Retrieved December 20, 2007, from University of Minnesota, Rural Families Speak Web site: http://fsos.cehd.umn.edu/projects/rfs/publications.html

Berry, A., Katras, M. J., Sano, Y., Lee, J. \& Bauer, J. W. (2008). Job volatility of rural, low-income mothers: A mixed methods approach. Journal of Family and Economic Issues, 29, 5-22. DOI 10.1007/s10834-007-9096-1

Bronfenbrenner, U. (1979). The ecology of human development: Experiments by nature and design. (Cambridge, MA: Harvard University Press).

Bronfenbrenner, U. (1986). Ecology of the Family as a Context for Human Development: Research Perspectives. Developmental psychology, 22, 723742.

Bubolz, M. M. \& Sontag, S. (1993). Human ecology theory. (In W. J. Doherty, P. G. Boss, R. LaRossa, W. R. Schumm \& S. K. Steinmetz (Eds.), Sourcebook of family theories and methods: A contextual approach (pp. 419-448). New York: Plenum.)

Bubolz, M. M. \& Whiren, A. P. (1984). The family of the handicapped: An ecological model for policy and practice. Family Relations, 33, 5-12. DOI $10.2307 / 584584$

Casey, P., Goolsby, S., Berkowitz, C., Frank, D., Cook, J., Cutts, D., et al. (2004). Maternal depression, changing public assistance, food security, and child health status. Pediatrics, 113, 298-304. DOI 10.1542/peds.113.2.298 
Cohen, R., Kim, M. \& Ohls, J. (2006). Hunger in America: National report prepared for America's Second Harvest. Retrieved December 20, 2007, from http://www.hungerinamerica.org/export/sites/hungerinamerica/about_the_stu dy/A2HNationalReport.pdf

Connell, C. L., Yadrick, K., Hinton, A. \& Su, J. (2001). Food insufficiency and the use of food assistance programs in the South. Retrieved December 20, 2007, from Mississippi State University, Southern Rural Development Center Web site: http://srdc.msstate.edu/focusareas/health/fa/fa_1.pdf

Dolan, E. M., Seiling, S. B. \& Glesner, T. (2006, February). Making it work: Rural low-income women in service jobs. (Paper presented at the Eastern Family Economics and Resource Management Association Conference, Knoxville, TN). Retrieved December 20, 2007, from http://mrupured.myweb.uga.edu/conf/5.pdf

Edin, K. \& Lein, L. (1997). Making ends meet: How single mothers survive welfare and low-wage work. (New York: Russell Sage Foundation).

Edwards, M. E., Weber, B. \& Bernell, S. (2006). Identifying factors that influence state-specific hunger rates in the U.S.: A simple analytic method for understanding a persistent problem. Social Indicators Research, 81, 579-595. DOI 10.1007/s11205-006-0026-7

Federal Register. (2005). Annual update of the HHS poverty guidelines. Retrieved December 20, 2007, from http://aspe.hhs.gov/poverty/05fedreg.htm

Hamelin, A., Habicht, J. \& Beaudry, M. (1999). Food insecurity: Consequences for the household and broader social implications. Journal of Nutrition, 129, 525S-528S.

Harvey, M., Summers, G., Pickering, K. \& Richards, P. (2002). The Short Term Impacts of Welfare Reform in Persistently Poor Rural Areas. (In B. A. Weber, G. J. Duncan \& L. A. Whitener (Eds.), Rural Dimensions of Welfare Reform (pp. 375-410). Kalamazoo, Michigan: W.E. Upjohn Institute for Employment Research.)

Huddleston-Casas, C. \& Braun, B. (2006). Rural families speak out III: Laboring towards economic self-sufficiency. (Webcast). Retrieved December 20, 2007, 
from University of Minnesota, Rural Families Speak Web site:

http://breeze5.umn.edu/maypresentation

Kirkpatrick, S. \& Tarasuk, V. (2003). The relationship between low income and household food expenditure patterns in Canada. Public Health Nutrition, 6, 589-897. DOI 10.1079/PHN2003517

Lichter, D. T. \& Jensen, L. (2002). Rural America in transition: Poverty and welfare in the turn of the twenty-first century. (In B. A. Weber, G. J. Duncan \& L. A. Whitener (Eds.), Rural Dimensions of Welfare Reform (pp. 77-110). Kalamazoo, Michigan: W.E. Upjohn Institute for Employment Research.)

Mayer, S. E. \& Jencks, C. (1989). Poverty and the distribution of material hardship. The Journal of Human Resources, 24, 88-114. DOI $10.2307 / 145934$

McIntyre, L., Glanville, T., Raine, K. D., Dayle, J. B., Anderson, B. \& Battaglia, N. (2003). Do low-income lone mothers compromise their nutrition to feed their children? Canadian Medical Association Journal, 168, 686-691.

Mirowsky, J. \& Ross, C. E. (1999). Economic hardship across the life course. American Sociological Review, 64, 548-569. DOI 10.2307/2657255

Molcho, M., Gaghainn, S. N., Kelly, C., Friel, S. \& Kelleher, C. (2007). Food poverty and health among schoolchildren in Ireland: Findings from the health behaviour in school-aged children (HSBC) study. Public Health Nutrition, 10, 264-370. DOI 10.1017/S1368980007226072

Monroe, P. A., O’Neill, C., Tiller, V. V. \& Smith, J. (2002). The challenge of compliance: Food security in rural households affected by welfare reform. Food assistance needs of the South's vulnerable population. Retrieved December 20, 2007, from Mississippi State University, Southern Rural Development Center Web site: http://srdc.msstate.edu/focusareas/health/fa/fa_5_monroe.pdf

Nord, M., Andrews, M. \& Carlson, S. (2005). Household food security in the United States, 2005. (Economic Research Report No. 29). United States Department of Agriculture, Economic Research Service. Retrieved December 20, 2007, from http://www.ers.usda.gov/Publications/ERR29/ 
OECD. (n.d.). OECD.stat extracts. Retrieved December 20, 2007, from http://stats.oecd.org/wbos/default.aspx

Parra-Cardona, J. R., Bulock, L. A., Imig, D. R., Villarruel, F. A. \& Gold, S. J. (2006). "Trabajando duro todos los dias": Learning from the life experiences of Mexican-origin migrant families. Family Relations, 55, 361-375. DOI 10.1111/j.1741-3729.2006.00409.x

Quandt, S. A., Arcury, T. A., Early, J., Tapia, J. \& Davis, J. D. (2004). Household and food security among migrant and seasonal Latino farmworkers in North Carolina. Public Health Reports, 119, 568-576. DOI 10.1016/j.phr.2004.09.006

Radimer, K. L., Olson, C. M. \& Campbell, C. (1990). Development of indicators to assess hunger. Journal of Nutrition, 120, 1544-1548.

Ribar, D. C. \& Hamrick, K. S. (2003). Dynamics of poverty and food sufficiency. (Food Assistance and Nutrition Research Report No. 36). Economic Research Service, U.S. Department of Agriculture. Retrieved December 20, 2007, from http://www.ers.usda.gov/Publications/FANRR36/

Rueben, K., Hoo, S. \& Yilmaz, Y. (2006). Fiscal Capacity of States, Fiscal 2002. Retrieved December 20, 2007, from Urban Institute and Brookings Institution, Tax Policy Center Web site: http://www.urban.org/publications/1001039.html

Sarlio-Lahteenkorva, S. \& Lahelma, E. (2001). Food insecurity is associated with past and present economic disadvantage and body mass index. Journal of Nutrition, 131, 2880-2884.

Tapogna, J., Suter, A., Nord, M. \& Leachman, M. (2004, October). Explaining variations in state hunger rates. (Paper presented at the 2004 Fall Research Conference of the Association for Public Policy Analysis and Management, Atlanta GA).

Tarasuk, V. (2001). Household food insecurity with hunger is associated with women's food intakes, health and household circumstances. Journal of Nutrition, 131, 2670-2676. 
Townsend, M. S., Peerson, J., Love, B., Achterberg, C. \& Murphy, S. P. (2001). Food insecurity is positively related to overweight in women. Journal of Nutrition, 131, 1738-1745.

UNDP. (2007). 2007/2008 Human development report. Retrieved December 20, 2007, from United Nations Development Programme Web site: http://hdr.undp.org/en/media/hdr_20072008_en_complete.pdf

Vailas, L. I., Nitzke, S. A., Becker, M. \& Gast, J. (1998). Risk indicators for malnutrition are associated inversely with quality of life for participants in meal programs for older adults. Journal of American Dietetic Association, 98, 548-553. DOI 10.1016/S0002-8223(98)00123-0

Weber, B. \& Jensen, L. (2004). Poverty and place: A critical review of the rural poverty literature. Retrieved December 20, 2007, from Working paper series, Rural Poverty Research Center Web site: http://www.rprconline.org/WorkingPapers/WP0403.pdf

Whitaker, R. C., Phillips, S. M. \& Orzol, S. M. (2006). Food insecurity and the risks of depression and anxiety in mothers and behavior problems in their preschool-aged children. Pediatrics, 118, 859-868. DOI 10.1542/peds.20060239 